\title{
COMO AQUí, ALLÁ; COMO NOSOTROS, ELLOS: LA INTERNACIONALIZACIÓN DE LA PRECARIEDAD EN EL EJERCICIO CIUDADANO
}

\author{
Patricia Zamudio Grave
}

Resumen: La universalidad de los derechos humanos ha sido proclamada y reiterada por la comunidad de naciones, desde mediados del siglo veinte. Al mismo tiempo, procesos globalizadores parecen contradecir el derecho de todos los seres humanos a gozar de una vida digna, en todos los aspectos que ésta engloba, tanto en países desarrollados, como en aquéllos en proceso de desarrollo. Este trabajo reflexiona sobre la forma como la migración internacional conectaexperiencias de precariedaden el ejercicio de derechos y sus consecuencias para la vida cotidiana de los migrantes.

Palabras clave: derechos humanos, ciudadanía, pobreza, migración internacional.

Enviado a dictamen: 16 de mayo de 2007

Aprobación: 22 de agosto de 2007.

Patricia Zamudio Grave, doctora en sociología por Northwestern University, investigadora del CIESAS-Golfo desde 2000, temas de especialización: migración internacional, ciudadanía y derechos humanos, correo electrónico: zamudiograve@ciesas-golfo.edu.mx,patzam28@yahoo.com.

66
Abstract. The universality of human rights has been proclaimed and reiterated by the community of nations, since the middle of last century. At the same time, globalizing processes seem to contradict the right of all human beings to enjoy a decent life, in all its aspects, either in developed countries or in developing ones. This work reflects on the way international migration connects experiences of precariety in the exercise of rights and its consequences for migrants' everyday life.

Key words: human rights, citizenship, poverty, international migration.

$\mathrm{N}$ ombrar un proceso social es en sí mismo un acto constructivo y, por ello, sujeto a enmiendas. Inicialmente, este trabajo se llamó, "Ni aquí, ni allá; ni nosotros, ni ellos: La Internacionalización de la Precariedad en el Ejercicio Ciudadano de los Veracruzanos". El cambio de nombre obedece al propósito de, en vez de oponer la realidad de dos espacios, aparentemente separados, reconocer su interrelación; en vez de particularizar el proceso, universalizarlo. La universalización de los derechos humanos fue proclamada por las Naciones Unidas desde mediados del siglo pasado, con la Declaración Universal de los Derechos Humanos, adoptada por su Asamblea General, en diciembre de 1948. A cincuenta años de dicha proclamación, en 1998, con la consigna de, "todos los derechos humanos para todos", las Naciones 
Unidas reafirmaron su compromiso de promover condiciones propicias para el ejercicio de derechos en todo el mundo. Dicha reafirmación se reiteró en abril de 2006, destacando que "todos los derechos humanos son universales, indivisibles, interrelacionados, interdependientes y se refuerzan mutuamente", y que todos los derechos humanos merecen recibir el mismo énfasis (Naciones Unidas, 2006). Además de ampliar el espectro de derechos, el afirmar su universalidad lleva a que su ejercicio trascienda condiciones de estatus de pertenencia a una comunidad nacional (Soysal, 2004).

$\mathrm{Al}$ mismo tiempo, procesos globalizadores han incrementado la pobreza y la precariedad en el ejercicio de derechos entre quienes no han podido responder a los retos de la apertura de mercados y otros procesos globalizadotes (ver Harris, 2006). La contradicción entre el compromiso universal de promover "todos los derechos para todos" y la creciente precarización en las condiciones de vida de grandes masas de personas se hace cada vez más evidente. Dicha precarización, sin embargo, no sólo sucede en países "en desarrollo", como México, sino también en países asumidos como desarrollados, tales como los Estados Unidos.

La experiencia migratoria internacional ayuda a comprender las interrelaciones entre espacios y la universalidad de procesos de reafirmación de los derechos para todos, así como la precariedad del ejercicio de los mismos. Esto sucede así porque los migrantes internacionales conectan, con sus cuerpos, con sus relaciones, territorios que también están conectados por las dinámicas económicas y políticas globales globalizadoras, que responden a modelos que privilegian la acumulación desmedida de riqueza por unos cuantos sobre el bienestar de las grandes mayorías. Por ello, la precariedad en la forma de vida que experimentan muchos migrantes mexicanos en los Estados Unidos se entrelaza, al tiempo que interroga, aquélla que experimentan ciudadanos estadounidenses en aquel país y ciudadanos mexicanos en México. Este trabajo se refiere a condiciones y experiencias de ejercicio precario de derechos entre algunos de los que conforman los "Dos Tercios del Mundo" (Mohanti, 2003), originarios de dos países y que han entrado en contacto gracias a la migración internacional.

A pesar de la universalidad de los procesos de precarización, la forma como dicha precariedad se expresa está ligada a las particularidades culturales, sociales, políticas y económicas del lugar en el que las personas - migrantes o no migrantes - residen y trabajan, tanto en México como en Estados Unidos. Algunos grupos se han convertido en el foco de prácticas discriminatorias: en el sur de los Estados Unidos, por ejemplo, una amplia proporción de la población afro-americana ha estado sujeta a prácticas racistas que la han colocado en los estratos más bajos de la escala social, tal como ha sucedido en Alabama. En dichos lugares, los migrantes indocumentados se enfrentan, entonces, a estructuras de confrontación racial existentes que los incorporan y que, al parecer, recrudecen la conflictividad entre ellos y los miembros de las sociedades en las que se insertan.

Para los migrantes, la selección del lugar de residencia está condicionada, en gran medida, por las oportunidades laborales a que pueden acceder. Como sucedió con Osiel, del Llano (Teocelo, Veracruz), quien cruzó la frontera con compañeros jornaleros de los campos cañeros de Tuzamapan, con destino a Carolina del Sur, para trabajar en la agricultura. Al llegar ahí, no había trabajo para él. Acudió entonces a una iglesia bautista y, "por mera casualidad", lo contactó una persona que buscaba trabajadores para una fábrica de trailas en Alabama. Osiel fue el pionero de la migración llanera al sureste norteamericano, principalmente a Alabama y a Mississippi. ${ }^{1}$ El y sus paisanos han tratado de mantener un compromiso laboral con su destino y un compromiso filial con su origen, cumpliendo diligentemente con sus trabajos, al tiempo que envían dinero a sus familias y se comunican con ellas regularmente. A pesar de ello, la precariedad de sus condiciones de vida y las de sus familiares son permanentes y no muy distintas a aquélla de muchos de los miembros de las comunidades de los lugares donde ahora laboran. El estatus migratorio, 
COMO AQUUí, ALLÁ; COMO NOSOTROS, ELLOS:

LA INTERNACIONALIZACIÓN DE LA PRECARIEDAD EN EL

EJERCICIO CIUDADANO

T e máti c a

origen étnico y condición de clase ayudan a comprender, tanto la agencia de migrantes y no migrantes y sus familias en la construcción de condiciones de ejercicio ciudadano y mejoramiento de su bienestar, como el éxito limitado en la consecución de sus objetivos.

Las reflexiones que siguen surgen de varios años de trabajo de investigación en la región central de Veracruz y en algunos de los lugares de destino de los migrantes veracruzanos, principalmente en California, Alabama y Mississippi.

\section{Imágenes de precariedad ciudadana aquí, en México}

Las historias de los llaneros hablan de largas esperas para construir magros patrimonios, de trabajo jornalero estacional para complementar los ingresos familiares y para construir la casa-habitación por habitación, cada techo, cada ventana, cada puerta. Sus historias hablan de café, de la caída de sus precios, de la esperanza de que "den la vuelta". Educación, trabajo, vivienda y salud se han solventado con lo mínimo. La jerarquía social de su comunidad es simple: ahí viven los pobres y los más pobres. La migración internacional está complejizando esta jerarquía, mejorando las condiciones de vida de algunos, profundizando las diferencias socioeconómicas y empezando a conformar lo que parece una nueva categoría de habitantes: los migrantes y sus familias.

El Llano es una comunidad cafetalera, situada en la región cafetalera de Coatepec, segunda productora del grano en Veracruz. Durante décadas, el estado mexicano apoyó la producción del aromático, básicamente a través del Banco Nacional de Crédito Ejidal y del INMECAFE, creado en 1958. Este último proporcionaba beneficios diversos a los productores, tales como apoyos en dinero y en especie para la producción, además de asesoría técnicay seguridad en los precios (Paredes, 1995). El auge cafetalero mundial fue esencial para que el estado pudiera sostener su apoyo a los productores y para que éstos continuaran mejorando su nivel de vida familiar y comunitario, siempre en condiciones de pobreza, como lo platica don Fausto:
Toda la gente [era] pobre, pero unida: [logramos tener] agua, luz, tienditas, campo deportivo, telesecundaria y [casa] de salud. (...) El gobierno puso la mayor parte, nosotros, la mano de obra. Las casas las está haciendo la juventud. Ya nosotros no pudimos hacer eso (don Fausto, Llano Grande, 2004).

La implementación de políticas económicas de corte neoliberal en México propició que, desde principios de los años ochenta, la participación del estado en el mundo cafetalero empezara a declinar, lo cual, paralelamente a las crisis recurrentes del precio internacional del café - debidas al rompimiento del pacto cafetalero internacional y a la introducción de grandes excedentes internacionales- propició una crisis en el sector cafetalero mexicano. De 1989 a 1994, los ingresos obtenidos por el café se redujeron en un 50\% (Paredes, 1995), lo cual golpeó duramente a las comunidades mexicanas dedicadas a su producción. En 1989, el INMECAFE se retiró de las funciones de financiamiento, acopio, beneficio y comercialización del grano, "suprimió los permisos previos de exportación y liberó el mercado interno, eliminando el precio de garantía, el recuento de existencia y la obligación de abasto industrial, y puso en venta [sus] plantas agroindustriales" (Paredes, 1995: 79). Así lo relata don Fausto:

Cuando estaba el Instituto, las oficinas en García, por las Trancas, pusieron una compra de café acá, del Instituto. Pedimos dinero para hacer una bodega: entregas el café, el gobierno daba abono y anticipos. Fui presidente del grupo. Mucha gente del [Monte, las Tejas y el Llano] estábamos unidos en el mismo Instituto. Entregabas todo el café, te daban un anticipo y lo demás iba quedando y cuando lo vendíamos, daban la liquidación. [En los ochenta,] empezaron a no querernos dar. Hicimos plantones hasta que nos dieron. Otro año igual. Hicimos plantones y manifestaciones, hasta que perdió el Instituto y tenías que comprar abono (don Fausto, Llano Grande, 2004.) 
El retiro del estado del apoyo a la producción fue profundamente perjudicial, tanto para productores medianos y pequeños como para jornaleros, al reducirse la seguridad en la comercialización y en el jornal. Las condiciones de bienestar y de ejercicio de derechos de los llaneros, frágiles de por sí, se deterioraron profundamente. Para 2004, los indicadores de bienestar de los miembros de la comunidad mantienen la precariedad, particularmente en el nivel educativo y en los ingresos. El promedio de años de estudio de los llaneros es la mitad del nacional, con tres cuartas partes de su población de 15 años o más con sólo algún estudio de educación elemental (Tabla 1). Nadie en el Llano ha asistido a la universidad. Estudiar la preparatoria constituye un gran problema para muchas familias, porque el telebachillerato está en una comunidad cercana y los estudiantes deben pagar diez pesos para ir y volver en el autobús, o llegar a pie, caminando tres y medio kilómetros. Además, las familias esperan que todos sus miembros cooperen en la obtención de recursos para el sustento y no les resulta fácil prescindir del trabajo de alguno de ellos. El Programa Oportunidades ha permitido a algunos jóvenes resolver parcialmente esta situación.

\begin{tabular}{|l|c|c|}
\hline \multicolumn{3}{|c|}{ Tabla 1. Nivel educativo } \\
\hline \hline Nivel Educativo* & El Llano & Promedio Nacional \\
\hline \hline Sin instrucción & $6 \%$ & $10 \%$ \\
\hline \hline Primaria & $\mathbf{7 6 \%}$ & $38 \%$ \\
\hline \hline Secundaria & $14 \%$ & $24 \%$ \\
\hline \hline Preparatoria & $4 \%$ & $17 \%$ \\
\hline \hline Universidad & $\mathbf{0 \%}$ & $11 \%$ \\
\hline $\begin{array}{l}\text { Promedio de años } \\
\text { realizados }\end{array}$ & 3.5 & 7 \\
\hline
\end{tabular}

* Porcentaje de población de 15 años y más con al menos un año cursado del nivel correspondiente.

Fuente: Elaboración propia con base en el archivo persfilel07. mmp. 2004. Datos consistentes con ITER 2000.
Los ingresos de la población ocupada ilustran también la precariedad de las condiciones de vida de los llaneros. La gran mayoría recibía, en 2004, dos salarios mínimos o menos. ${ }^{2}$ Las ocupaciones con tan bajo ingreso corresponden a la venta de alimentos desde la casa ${ }^{3}$ y a la venta de hortalizas o animales de traspatio, entre otras. Las labores remuneradas de la comunidad están relacionadas principalmente con las actividades culturales del café, con un jornal que fluctúa entre sesenta y ochenta pesos, y con el trabajo en pequeños talleres artesanales y en servicio doméstico, en la ciudad de Coatepec.

\begin{tabular}{|l|c|}
\hline \multicolumn{2}{|c|}{ Tabla 2. Ingresos de la población ocupada, 2000} \\
\hline \hline Ingresos & Llano Grande \\
\hline \hline SIN INGRESOS & $21 \%$ \\
\hline \hline MENOS DE 1 SM & $\mathbf{3 8 \%}$ \\
\hline \hline 1 A 2 SM & $\mathbf{3 7 \%}$ \\
\hline \hline 2 A 5 SM & $3 \%$ \\
\hline \hline 6 A 10 SM & $0 \%$ \\
\hline \hline 10 Y MAS & $0 \%$ \\
\hline \hline DE O A 2 SALARIOS MINIMOS & $96 \%$ \\
\hline
\end{tabular}

Fuente: ITER 2000.

En una comunidad rural, la tierra es crucial para entender las condiciones de vida de sus habitantes. El Llano recibió tierras en ejido, durante los años treinta. Correspondió a cada ejidatario una dotación de 5 hectáreas de temporal, en terrenos que combinan pequeñas áreas planas con grandes laderas. Los ejidatarios continuaron con las tradiciones productivas de sus regiones, cultivando caña o café, entre otros productos. Las pequeñas parcelas, poco fértiles y en laderas, fueron adecuadas para la producción cafetalera. ${ }^{4}$

El reparto agrario no benefició a todos los miembros de la comunidad. Además, con el tiempo, las dotaciones 
COMO AQUí, ALLÁ; COMO NOSOTROS, ELLOS:

LA INTERNACIONALIZACIÓN DE LA PRECARIEDAD EN EL

fueron dividiéndose, entre los hijos, manteniendo un proceso constante de atomización de tierra (ver Cruz, 2003). Esta dinámica perjudicó a los llaneros de forma significativa, por lo reducido de la dotación original y por la baja calidad de la tierra. En general, la desigualdad socioeconómica interna de las comunidades rurales tiene que ver con estos procesos y el Llano también refleja sus efectos, en una comunidad en la que, actualmente, sólo $63 \%$ de los hogares tiene tierra propia ( $92 \%$ de ejido).

\begin{tabular}{|l|c|}
\hline \multicolumn{2}{|c|}{ Tabla 3. Caracteristicas de la propiedad de la tierra } \\
\hline \hline características & Llano Grande \\
\hline \hline Hogares totales en la comunidad & 287 \\
\hline \hline Hogares con tierra & 182 \\
\hline \hline$\%$ de hogares con tierra propia* & $\mathbf{6 3} \%$ \\
\hline \hline Privada & $8 \%$ \\
\hline \hline Ejido & $92 \%$ \\
\hline
\end{tabular}

* $100 \%$ de la tierra es de temporal.

Fuente: Elaboración propia con base en el archivo housefilel07, mmp. 2004.

Poseer tierra no es una garantía para alcanzar o mantener niveles mínimos de bienestar; por ello, la migración internacional empezó a formar parte de las estrategias de reproducción cotidiana de las familias,

Yo no me he ido ahorita, por el problema que tuve, pero me dan ganas de irme ya, pu's no me da. Aquí, pa' lo poco que me gano por semana, na' más me da pa' comer; si quieres vestir, pu's no. Me gano trescientos cincuenta pesos a la semana. [Me quedo] nomás por la cosecha de café, que apenas viene y así nos vamos a recuperar tantito, pero na' más es una pasada. En tiempo de mango también me va más o menos, a’i sí junto más dinero que con el café. Aquí el que tiene, tiene, el que no, no tiene (don Antonio, Llano, 2005).
A pesar de la crisis cafetalera, la mayoría de las tierras se dedican a la producción del grano, en pequeñas extensiones de tierra de temporal —en el Llano, la extensión de la mayoría de las fincas es de menos de una hectárea. A partir de diciembre, y hasta marzo, los productores lo cosechan y lo venden "en cereza" a intermediarios, para su beneficio y posterior comercialización. ${ }^{5}$ Hasta los años ochenta, los ingresos obtenidos por el café (combinado, en muchos casos, con la migración jornalera regional) permitieron a las familias mejorar poco a poco sus condiciones de vida; muchos iban construyendo sus casas por partes, con los ingresos de cada cosecha y de cada migración. Así fue hasta principios de los años noventa, cuando la crisis internacional de los precios y la creciente desprotección de los productores llevó a los llaneros a cruzar fronteras.

Figura 1. Destinos de los Llaneros en Estados Unidos

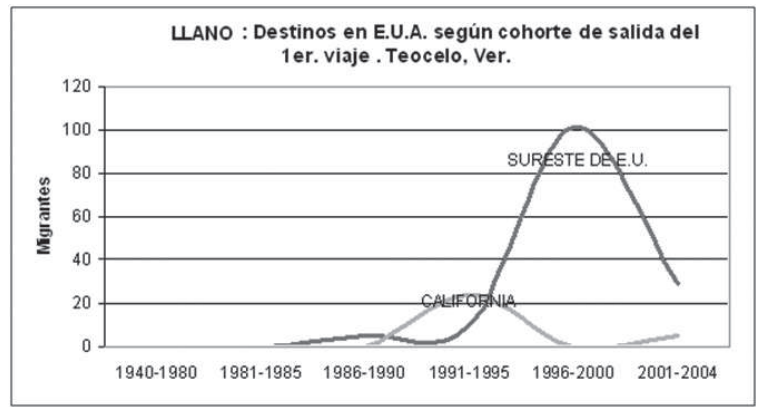

Precariedades crecientes, expresadas en magros ingresos, bajos niveles educativos y escasas probabilidades de que los precios del café "den la vuelta", entre otras cosas, han propiciado el crecimiento acelerado de la migración internacional desde el Llano, principalmente a partir de 1995. Para 2004, de una población de poco más de 1244 llaneros, 231 estaban en los Estados Unidos, la mayoría en los estados del sureste (Figura 1). 


\section{Imágenes de precariedad allá, en Estados Unidos}

Los llaneros que viven en los Estados Unidos, casi sin excepción, son migrantes indocumentados. Dicha condición los coloca, como a muchos otros, en el centro de la contradicción entre representar un "beneficio", a la vez que un "reto", para aquel país. Porque los migrantes ayudan a Estados Unidos a ser más productivo, competitivo y exitoso en el siglo XXI (Spencer et.al., 2006). Al mismo tiempo, sin embargo, existen importantes retos que la migración presenta, principalmente por la presencia de una gran cantidad de migrantes indocumentados, que se estima en casi 12 millones. Esta situación interroga el sistema legal, así como la seguridad fronteriza, y genera otros riesgos, tanto para el país en su conjunto como para los migrantes mismos, que se encuentran en condiciones de gran vulnerabilidad.

Las tensiones sociales también pueden profundizarse con la presencia de migrantes indocumentados, que se emplean principalmente en trabajos de baja calificación y compiten con los miembros de los sectores más desprotegidos de la ciudadanía americana. Su presencia tiene efectos sobre los salarios de la población nativa, particularmente en los sectores de bajo ingreso, generando tensiones entre grupos étnicos, como han experimentado los llaneros en el estado de Alabama. Y, como en otros estados con poca tradición de inmigración, las comunidades están apenas aprendiendo a responder a la llegada de migrantes y a desarrollar estrategias, tanto institucionales como comunitarias, para incorporarlos. La presencia de migrantes internacionales en Alabama se duplicó entre 1990 y 2000, pasando de 42 mil a 88 mil. La población mexicana creció enormemente: de 1155 en 1990, a 27,103 en 2000 (Camarota y McArdle, 2003).

Los "retos" que la migración indocumentada presenta a aquel país cobran vida en la experiencia diaria de los migrantes. Los llaneros no se quejan de las condiciones laborales que han encontrado, todo lo contrario. Para ellos, "trabajar en la sombra", en una fábrica de trailas o de muebles, es mucho mejor que "poner el lomo al sol", en los campos de caña, de café o de naranja, sembrando o cosechando, a cambio de unos cuantos pesos. Es por eso que los migrantes "quieren vivir diferente", como don Luis, llanero que trabaja en Alabama, instalando bisagras en puertas de madera,

[Me gusta más trabajar] aquí. Sí, porque ganas más y es más fácil; no trabajas tanto, vaya, es un poco menos pesado que allá. [L]os papás de uno lo enseñan a trabajar. Y [pienso] que está bien pues, la labor del campo. Pero uno luego quiere vivir diferente, buscar una vida; y hay que salir, porque la vida de allá es diferente a la de aquí (don Luis, Alabama, 2006).

La mayoría de los llaneros migrantes siguió la ruta inaugurada por Osiel, asentándose principalmente en Alabama, ${ }^{6}$ para trabajar, en su mayoría, en la manufactura de trailas o de gabinetes. Osiel y otros se beneficiaron del crecimiento de la industria maderera en el estado, cuya superficie se encuentra cubierta por bosques en un $71 \%$, lo que la convierte en el "segundo bosque comercial en la nación”, según la Alabama Forestry Comisión (AFC). Para muchos, la industria maderera es la más importante del estado, con más de 1,100 compañías en este ramo y cerca de 70 mil trabajadores, más casi 100 mil que dependen indirectamente de ella (AFC, 2006). En total, 13\% de la fuerza de trabajo de Alabama trabaja en actividades relacionadas con esta industria, incluyendo a la mayoría de los llaneros en el estado.

Don Cristóbal, otro llanero en Alabama, explica por qué prefiere el trabajo en una fábrica de trailas sobre aquél que se lleva a cabo en el Llano,

Bueno, pienso que para mantenerse para la comida y eso, pienso que [allá] está bien, pues, al no haber otro trabajo, pienso que [hay] que trabajar, pues. De hecho, a mí sí me gusta; pues para mí lo que te pongan a trabajar, mientras te paguen un precio más o menos, que no sea ni tan bajo. Pero sobre el trabajo de mi papá pienso que está bien, es el oficio 
COMO AQUí, ALLÁ; COMO NOSOTROS, ELLOS:

LA INTERNACIONALIZACIÓN DE LA PRECARIEDAD EN EL

EJERCICIO CIUDADANO

que tienen mis hermanos los mayores, es un oficio que tienen y de ellos se mantienen; sobreviven pues, están contentos con su trabajo, están cerca de su familia, no tienen que estar en otro lado. Pienso que está bien pues (don Cristóbal, Alabama, 2006).

Los salarios que reciben los llaneros que trabajan en Alabama son superiores a los que recibían en el Llano. Mientras en su tierra lo máximo que se obtiene a la semana son 350 pesos, en Estados Unidos, doscientos dólares semanales les parecen poco; como sucedió con don Mario, quien probó diversos lugares y trabajos, antes de estar satisfecho con su salario,

Pues, sí, mire. Primero llegué a trabajar [...] en el tabaco; de ahí, me consiguieron un trabajo en un campo de golf, pero nada más ganaba doscientos dólares por semana; pues yo, doscientos dólares me parecía poco. [...] "Andale, le dije [al contratista], ya no me esta gustando mi trabajo y probablemente yo te voy hablar para que me des [otro] trabajo". [...] Entonces, una semana estuve trabajando y ya el jueves me dieron mi cheque, el sábado conseguí rai y que me voy a la casa del contratista. [...] Ya le dije, "ya traigo mis cosas vengo porque quiero que me des trabajo". Me dice, "sí, Marcos, tú has sido un buen trabajador", me dijo. Y, de veras, porque yo trabajé para él y él me conoce que soy responsable-porque los patrones es lo que quieren, que uno sea responsable en el trabajo, que uno no falte, que uno haga las cosas a tiempo, si uno está cansado y te dicen "vas a salir a las seis", "vas a salir a las ocho", no importa la hora, porque a eso venimos. Entonces yo, mi manera de pensar es ésa, porque yo vine a trabajar, a echarle ganas; no importa que yo esté cansado yo sigo trabajando hasta que me digan "ya vámonos". [...] Y cuando yo llegué con mis cosas, le dije "isabes que?, yo ya traje mi cosas y vine a que me dieras trabajo. Me dice, "sí, mira, mañana te voy a llevar otra vez a Virginia, te voy a mandar a mi chofer”. [...] Y nos fuimos. Entonces, ahí iba el hermano de él, y me dice, "Marcos, ¿qué tiempo piensas estar aquí?" "Pues yo le tiro a dos años", le dije. "Está bien. ¿En el mismo trabajo?" Y le dije, "Si a donde me van a llevar, me gusta el trabajo, yo ahí me quedo [...]; pero que me guste el cheque, porque si veo que el cheque sale más o menos yo ahí me quedo, de ahí salgo a México. Pero si no, lo siento mucho, cobro un cheque y yo le busco; porque yo a eso vine, yo voy a luchar, le dije, a donde me paguen mejor, a donde me paguen un poquito más, porque yo tengo familia en México que mantener, le dije, se supone que yo dejé de verlos para venir para acá y yo tengo que buscar donde gane un poquito mejor". Y sí, ya llegamos a un rancho, pero lejísimos, donde no había tienda; era un monte por allá, un aserradero que estaba por allá (don Mario, Alabama, 2006).

Es claro para los migrantes, como don Mario, que la separación de la familia es un costo que pagan por acceder a mejores ingresos. Por ello, estos migrantes no aceptan salarios que consideran bajos, aunque considerablemente mayores a los de su comunidad de origen. Así que don Mario dejó también el nuevo trabajo, porque pagaba poco (sólo doscientos dólares a la semana) y buscó otro, ayudado por sus paisanos llaneros, en una fábrica de trailas, en Alabama, en donde ganaba 350 dólares semanales.

Así como los salarios, relativamente altos para ellos, otros aspectos de las condiciones laborales gustan a los llaneros,

Pues yo pienso que aquí [me gusta más trabajar], pues. Sí, pienso que aquí, porque, le digo, porque aquí tiene uno muchos derechos. Pues, por decir, si aquí trabajas cierto tiempo tienes aseguranza, tienes médico dental, médico de vista pues, tienes privilegios de vacaciones, y aparte que le pagan mucho mejor, mejor sueldo. Pienso que está mejor aquí, pues tan sólo en México, trabajando de albañilería, no tiene seguro medico, si usted se corta un dedo no tiene seguro medico, o no le pagan. (don Cristóbal, Alabama, 2006.)

72 Revista LiminaR. Estudios sociales y humanísticos, año 5, vol. V, núm. 2, diciembre de 2007, Tuxtla Gutiérrez, Chiapas. ISSN: 1665-8027 
El derecho al trabajo es ejercido por los llaneros en Alabama en condiciones que ellos perciben como relativamente favorables, en comparación con las condiciones que prevalecen en su comunidad y región de origen. Sin embargo, otros aspectos de la ciudadanía, relacionados con su condición humana, principalmente los que tienen que ver con el reconocimiento de los miembros de la sociedad de su calidad de seres humanos con derechos (ver Zamudio, 2006), han resultado de difícil acceso. Son aspectos de la ciudadanía que ponen de relieve las inequidades étnicas que han caracterizado a los estados del "sur profundo" estadounidense y que han colocado a otros miembros de "los dos tercios del mundo", particularmente a ciudadanos afro-americanos de Estados Unidos, en condiciones de precariedad del ejercicio ciudadano.

A pesar de que la economía de Alabama ha crecido en los últimos años y su tasa de desempleo es menor que la nacional (de 4\% y 5\%, respectivamente), las condiciones de vida de sus habitantes presentan grandes problemas. En 2005 la proporción de participación de la fuerza de trabajo en el estado era de 61.9\%, la más baja del país: casi 40\% de los habitantes del estado, de 16 años o más, habían abandonado el mercado de trabajo o nunca habían entrado en él. Los hispanos, sin embargo, tuvieron una tasa de $86 \%$, lo cual sugiere que, como dice don Cristóbal, los migrantes mexicanos "vienen a trabajar".

La inequidad se incrementa, entre otros factores, porque los beneficios del crecimiento económico se han distribuido de forma poco equitativa entre las zonas urbanas y suburbanas y las zonas rurales, éstas últimas caracterizadas por mayor presencia de ciudadanos afro-americanos. ${ }^{7}$ En 2005, la tasa desempleo de los trabajadores afroamericanos fue dos veces y media superior que la de los trabajadores blancos (Tabla 4) (ACPP, 2006).

\begin{tabular}{|l|r|r|c|}
\hline \multicolumn{3}{|c|}{ Tabla 4. Alabama. Tasa de desempleo } \\
\hline \hline & 1995 & 2000 & 2005 \\
\hline \hline Desempleo total & $6.4 \%$ & $4.5 \%$ & $4.2 \%$ \\
\hline \hline Desempleo por raza (sic) & & & \\
\hline \hline Blancos & $4.1 \%$ & $3.3 \%$ & $3.1 \%$ \\
\hline \hline Afroamericanos & $13.3 \%$ & $8.2 \%$ & $8.2 \%$ \\
\hline
\end{tabular}

Fuente: Economic Policy Institute. Analisis de los datos del Current Population Survey, 2005.

Los problemas laborales de Alabama se expresan en los ingresos de la población, que mantienen a algunos sectores en condiciones de pobreza. La tasa estatal alcanzó, en 2005, a 16.7\% de la población. En ese año, para que una familia con cuatro integrantes estuviera por encima del límite de pobreza (19,961 dólares anuales), debía contar con un trabajador de tiempo completo que ganara 9.60 dólares por hora. Más de un cuarto de los trabajadores no alcanzaron tal salario y 36 mil de ellos ganaban menos del salario mínimo federal, de 5.15 dólares. ${ }^{8}$ La inequidad entre etnias se inclina de nuevo en contra de la población afroamericana, que recibió, en el mismo año, el equivalente a 67\% de las percepciones de los trabajadores blancos. ${ }^{9}$

\begin{tabular}{|c|c|c|}
\hline & 1990 & 2000 \\
\hline \multicolumn{3}{|l|}{ Pobreza total } \\
\hline Personas en pobreza & $15.7 \%$ & $16.1 \%$ \\
\hline \multicolumn{3}{|l|}{$50 \%$ De pobreza } \\
\hline $\begin{array}{l}\text { Personas con ingresos debajo del } 50 \% \text { del } \\
\text { límite de pobreza }\end{array}$ & $6.5 \%$ & $7.0 \%$ \\
\hline \multicolumn{3}{|l|}{ Estado de alabama pobreza por raza (sic) } \\
\hline Blancos por debajo del nivel de pobreza & $11.7 \%$ & $10.5 \%$ \\
\hline Negros por debajo del nivel de pobreza & $37.7 \%$ & $31.3 \%$ \\
\hline Otras razas por debajo del nivel de pobreza & $21.1 \%$ & $20.3 \%$ \\
\hline \multicolumn{3}{|l|}{$\begin{array}{l}\text { Condado de calhoun } \\
\text { Pobreza por raza }\end{array}$} \\
\hline Blancos por debajo del nivel de pobreza & $12.3 \%$ & $12.6 \%$ \\
\hline Negros por debajo del nivel de pobreza & $31.5 \%$ & $31.1 \%$ \\
\hline Otras razas por debajo del nivel de pobreza & $6.8 \%$ & $19.8 \%$ \\
\hline
\end{tabular}

Fuente: Study of Persistent Poverty in the South, University of Georgia. 
COMO AQUÚ, ALLÁ; COMO NOSOTROS, ELLOS:

LA INTERNACIONALIZACIÓN DE LA PRECARIEDAD EN EL

EJERCICIO CIUDADANO

T e mátic a

Alabama es un estado de "bajos salarios", con ingresos menores a los promedios nacionales. Algunos sectores han visto crecer el promedio de salario por hora, pero no los afro-americanos, quienes, entre 2000 y 2005, lo vieron declinar en 2.2\% (Tabla 6). Un gran problema de Alabama es que no tiene una ley de salario mínimo. Aún si la tuviera, sus beneficios serían limitados, ya que el nivel adquisitivo de dicho salario se ha deteriorado en 20\% y es el más bajo desde 1955. Como consecuencia de estas condiciones, en Alabama, en 2005, 36.5\% de los trabajadores recibían menos de $200 \%$ del ingreso que define el nivel de pobreza.

\begin{tabular}{|c|c|c|c|c|c|}
\hline \multicolumn{5}{|c|}{ Tabla 6. Alabama. Salario por hora* } \\
\hline \hline & 1989 & 2000 & 2005 & $\begin{array}{c}1979 \text { a } \\
2005\end{array}$ & $\begin{array}{c}2000 \mathrm{a} \\
2005\end{array}$ \\
\hline \hline Salario general & $\$ 11.30$ & $\$ 12.30$ & $\$ 13.60$ & $13.14 \%$ & $10.57 \%$ \\
\hline \hline Salario por raza & & & & & \\
\hline \hline Blancos & $\$ 12.18$ & $\$ 13.48$ & $\$ 15.09$ & $16.35 \%$ & $11.94 \%$ \\
\hline \hline Afro-americanos & $\$ 8.73$ & $\$ 10.35$ & $\$ 10.12$ & $19.91 \%$ & $-2.22 \%$ \\
\hline
\end{tabular}

* Ajustado a dólares de 2005.

Fuente: Economic Policy Institute, Analisis de los datos de Current Population Survey, 2005.

A pesar de que se crearon 60 mil trabajos entre 2002 y 2005 , la mayoría fueron en el sector servicios (87\%), caracterizado por bajos salarios y magras prestaciones, ${ }^{10} \mathrm{y}$ hubo un decremento de $3.2 \%$ de salarios en el sector manufacturero. Otro aspecto de la disparidad creciente del mercado de trabajo de Alabama es la brecha que hay entre sectores, según sus ingresos. Entre 1979 y 2005, los salarios para los trabajadores con menores ingresos decrecieron en 3.1\%, mientras los salarios para aquéllos con los salarios más altos se incrementaron en $20.81 \%$. El condado de Calhoun, uno de los que albergan a los llaneros, presenta procesos y características similares a las del estado en su conjunto (Alabama Poverty Project, (APP) 2005).

Como en México, la precariedad en las condiciones laborales de Estados Unidos también crece, sobre todo para la población afro-americana. El decremento de los salarios, así como el empeoramiento de las condiciones laborales allí, sin embargo, no desalienta a los llaneros a continuar migrando. Ellos perciben dicho movimiento como inevitable, si quieren lograr su propósito de mejorar sus condiciones de vida y las de sus familias. Su migración, entonces, conecta dos espacios de precariedad de ejercicio de derechos ciudadanos. En la cotidianidad, el espacio de llegada se convierte en un campo de batalla, en donde migrantes y nativos se construyen mutuamente como enemigos, sin comprender cabalmente los procesos económicos y sociales globales que subyacen a la precariedad de sus vidas.

\section{Como aquí, allá}

Para muchos habitantes de Alabama, particularmente, para los afro-americanos, quienes han sufrido de discriminación añeja, la presencia de los migrantes mexicanos constituye un verdadero problema, porque éstos compiten por los escasos empleos y aceptan condiciones de trabajo precarias. Quizá porque, como decía don Mario, ellos a eso vienen, a trabajar, aunque se cansen. Su compromiso laboral, sin embargo, juega en contra de las condiciones laborales de todos los trabajadores. Así lo concibe don Cristóbal,

Pues, en realidad, el gobierno sabe que los mexicanos vienen a trabajar y todo. [...] Ellos saben que los mexicanos vienen a trabajar y no a quitarles el trabajo a los americanos. [...] Hay mucho trabajo que el americano no hace. Yo lo veo. En mi trabajo, va un americano tres o cuatro días y ya no va porque está pesado el trabajo; y hasta un moreno se sorprendió, porque me dice, "hey, icuánto tiempo te haces?" Porque el supervisor de él me preguntó, “oye, Cristóbal, ¿vas a trabajar mañana?, le dije, no, me dice, ino me quieres venir a ayudar mañana, porque tengo mucho trabajo en mi departamento? Sí, le dije." Ya me fui al otro día al departamento [...], y ya me puse a atrabajar. Y, me 
dice el moreno, que tenía como un mes de entrar a trabajar, me dice, "icuánto tiempo tienes trabajando aquí? Le digo, tres años. Es mucho tiempo. Y le digo, ¿Por qué? No, porque el trabajo está duro aquí”. [...] Y, en realidad el trabajo no está duro, sino que no están acostumbrados al trabajo. Pues, en realidad no está pesado sino son muchos detalles y ellos no quieren quebrarse la cabeza, no quieren hacer nada con las manos por decir, ah, si una maderita está mal puesta, no quieren levantarla, quieren que traigan la grúa para levantarla (don Cristóbal, Alabama, 2006).

Lo que don Cristóbal interpreta como falta de costumbre para trabajar es producto de la comparación que constantemente establece con su situación en el Llano, donde el trabajo agrícola es exhaustivo y se compensa con una magra remuneración. Ni don Cristóbal ni el moreno entienden, pues, que la situación histórica de explotación del segundo permite y perpetua la explotación actual del primero y de ambos. Y don Cristóbal piensa que el moreno es flojo (por resistirse a aceptar un trabajo tan pesado) y el moreno mira a don Cristóbal y a otros migrantes (indocumentados), no como personas que han querido escapar de un tipo de explotación mayor, en su lugar de origen, sino como aquéllos que devalúan sus propias condiciones de trabajo, al estar dispuestos a aceptar cualquier empleo. Estas condiciones reafirman la contradicción entre la pretendida promoción de la universalidad de los derechos humanos y los procesos económicos que impiden su ejercicio.

La percepción mutua tiene consecuencias cotidianas, para ambos grupos de trabajadores, en diferentes ámbitos. Por ejemplo, en el laboral, las burlas de los trabajadores americanos, particularmente de los afroamericanos, son frecuentes,

Pues, ahí donde estamos, había un moreno que me decía, bueno, que se burlaba. Yo le decía, "yo no soy mojado, si yo fuera mojado, estuviera trabajando aquí ilícito y tengo mas derechos que tú", le dije. Y si usted le pregunta a alguien que no sabe inglés, pues no sabe nada del país, pues se queda callado y no sé que onda, iverdad? Pero si uno sabe contestar, pues se quedan, "éste sí fue a la escuela o no fue pero sí sabe de cómo se mueve aquí en el país" (don Cristóbal, Alabama, 2006).

También son frecuentes las acciones criminales por parte de hombres afro-americanos contra los migrantes. Romper el vidrio de sus carros para robar sus estéreos es un hecho muy común. Y, cada semana, cuando los migrantes reciben sus cheques, se convierten en el blanco preferido de asaltos, por parte de ladrones afroamericanos. Muchos de ellos se apresuran a enviar dinero a México, para evitar ser despojados. También sus trailas son blanco de agresiones. Los viernes, los ladrones "se meten con pistola y todo" y roban dinero y bienes, tales como estéreos y televisiones. Y, como dice Brenda, miembro de una organización católica de asistencia a migrantes, ellos (los migrantes) "no dicen nada" porque tienen miedo a la deportación. Como muchos otros habitantes de Alabama, la mayoría de los llaneros vive en trailas y varios de ellos han sufrido asaltos y robos en sus carros y en sus casas.

Parte del problema de los asaltos se resolvería abriendo una cuenta de banco, pero los migrantes no confían en los servicios bancarios. Temen que si son deportados van a perder sus ahorros. El robo a sus trailas podría resolverse mudándose a una casa o departamento, en zonas más seguras. Sin embargo, la ruralidad de Alabama ofrece pocas opciones de habitación a precios accesibles, sobre todo, considerando que los migrantes tratan de ahorrar lo más posible en sus condiciones de vida locales para enviar una mayor cantidad de remesas al Llano.

El arrendamiento de habitaciones refleja también la discriminación étnica prevaleciente en Alabama. Los arrendatarios prefieren rentar a un latino, aunque sea migrante indocumentado, que a un afro-americano, porque consideran que éstos últimos son "problemáticos". Más allá de los procesos que alimentan dichos estereotipos, lo cierto es que la condición de ciudadanos 
COMO AQUÚ, ALLÁ; COMO NOSOTROS, ELLOS:

LA INTERNACIONALIZACIÓN DE LA PRECARIEDAD EN EL

estadounidenses que poseen los afro-americanos, que les permite reclamar formalmente sus derechos y exigir condiciones de vivienda adecuadas, los coloca -irónicamente- en una posición de desventaja en relación con quienes, por su condición de indocumentados, tienen (o asumen que tienen) un acceso restringido a instancias institucionales para denunciar un mal trato o reclamar el cumplimiento de las condiciones laborales o habitacionales acordadas.

La movilidad física también es un problema para los migrantes indocumentados del Llano. En las zonas rurales de Alabama, tener un carro es necesario para trasladarse al trabajo, como bien lo reconoce don Luis,

Entrevistador: ¿Cuánto se puso usted de meta para estar aquí?

Luis: Pues, uno dice que poquito, porque a veces piensa que va a hacer dinero rápido. Pero no, las cuentas las hace uno, pero no es cierto.

Entrevistador: Sí, después de pagar renta...

Luis: Pagas renta, después que te compraste un carro. [...] Aquí sin carro no hay trabajo (don Luis, Alabama, 2006).

Pero transportarse por los caminos rurales también constituye un riesgo para los migrantes indocumentados. Los retenes de la policía del condado son frecuentes:

El trato que les hacen a ellos es bien triste y aquí la verdad que por cualquier cosita los agarran, los paran, y es que estamos en un país, en un estado que es bien racista; ésa es la verdad, un estado bien racista (Brenda Bullock, Alabama, 2006).

Pues, la realidad como está la situación aquí, a veces se, como dice uno, se agüita uno pues, por la situación de que a veces uno no puede salir por el temor de que haya un retén, te van a parar, te van a dar tiques, te pueden llevar a la cárcel, te quitan tu carro. A veces, uno no puede viajar lejos porque piensa uno que puede estar migración, te puede agarrar, te puede llevar, pues. O sea, pues es algo que trae uno en la mente y que no se quita. O se sale uno, pero con el temor de que te pueden pasar muchas cosas; se siente como frustrado pues, pero en realidad se acostumbra, pues se acostumbra uno a la vida. Es todo de cómo se porte uno: si se porta mal, si anda tomando, así pues sí lo paran los policías, pero si se porta bien, pues pienso que nada le pasa, pues de salir y estar pensando en la migración, ya depende la suerte de cada quien, ya cada quien tiene marcada su suerte. Yo pienso en la suerte pues, si salgo un día pues en nombre sea de Dios, y si algo me va a pasar ya ni modo. Pero siempre pienso positivo, voy a regresar donde estoy y así, de hecho yo me he ido solito a Mississippi, viajando en la noche, me he ido de aquí a las doce de la noche (don Cristóbal, Alabama, 2006).

El traslado al lugar de trabajo es cotidiano, así que los migrantes no tienen alternativa sino confiar en su suerte o encomendarse a su Dios. Lo mismo deben hacer cuando van al mandado, cada semana, lo cual también constituye un riesgo para los migrantes indocumentados. Los llaneros cuentan que las redadas en el supermercado local, "Wal-Mart”, son frecuentes. Ellos han aprendido a huir por la puerta de la jardinería cuando ven que llegan los agentes de migración. A veces, cuentan con la solidaridad de algún ciudadano americano: hay un señor que vive cerca de Wal-Mart y les avisa cuando sabe que habrá redadas.

Wal-Mart es también escenario de agresiones verbales de afro-americanos hacia migrantes mexicanos. Los llaneros platican de varias ocasiones en las que un moreno les grita "ilegales" o los conmina, efusivamente, a que regresen a su país: "Mexican, go away!" Como vemos, "mientras los derechos adquieren una forma más universalista y se divorcian de la pertenencia nacional, (...) las identidades se hacen cada vez más particularistas, son acentuadas" (Soysal, 2004: 4) y se promueven medidas exclusionistas, principalmente en contra de los migrantes internacionales. 
Los conflictos entre los grupos étnicos han estado presentes en la historia del estado y aún continúan. Alabama es, en efecto, un estado racista. Las agresiones contra los migrantes no sólo proceden de los ciudadanos afro-americanos, también los blancos hacen lo suyo. Los miembros del Ku Klux Klan (KKK), que tradicionalmente han agredido a afro-americanos y a otros grupos, ahora también dirigen sus ataques hacia los migrantes, particularmente hacia los mexicanos. La Antidifamation League ha registrado diversos actos públicos de rechazo; por ejemplo, el 6 de mayo de 2006, miembros de dicha agrupación llevaron a cabo una manifestación anti-inmigración. Gritaban, “iDeshagámonos de los mexicanos!" Su líder decía a los participantes que los migrantes "te quieren fuera de aquí, porque quieren apropiarse de esta tierra." Después del mitin, los miembros del KKK quemaron una cruz en un campo en las afueras del pueblo (2005).

\section{Conclusiones}

Pues, como todos los mexicanos, queremos hacer dinero, hacer tu casa, hacerte de tus cosas y ya regresar. Y es la meta que todos tenemos, guardar dinero, hacer tu casa y regresar, pues (don Cristóbal, Alabama, 2006).

Los llaneros están cruzando la frontera y buscando trabajo en Estados Unidos para mejorar sus condiciones de vida y las de sus familias. No quieren sólo sobrevivir, sino "salir adelante". Su movimiento, sin embargo, los pone en contacto con ciudadanos de otro país, cuyas condiciones de vida son también precarias. De maneras distintas, pero entrelazadas, migrantes indocumentados mexicanos y sectores de la población afro-americana se han enfrentado a una explotación creciente de su capacidad laboral y, al mismo tiempo, al deterioro sostenido de su bienestar. La implantación del neoliberalismo a nivel global, responsable de muchos de sus males, también ha propiciado la intensificación de la migración internacional, proceso que ha puesto en contacto, de manera cotidiana, cara a cara, un aquí con un allá, ambos limitantes del ejercicio ciudadano pleno y ambos contradictorios de la universalidad de los derechos humanos tan proclamada por la comunidad de naciones, en su lema, "todos los derechos para todos".

Ambos limitantes y contradictorios, sí, pero no de la misma manera. Hay disparidades entre países que definen la dirección del movimiento migratorio: son los llaneros los que arriesgan la vida para llegar a Alabama y son los afro-americanos los que perciben su fragilidad social amenazada por un nuevo grupo. Y la cotidianidad de sus encuentros, en el trabajo, en la calle, en WalMart, no logra develar los procesos que los han reunido ni permitirles comprender que no son enemigos y que su condición de clase trasciende la de su origen étnico e, incluso, la de su ciudadanía formal. Al contrario, dicha cotidianidad sólo profundiza la mutua incomprensión y los mutuos estereotipos.

Los que estudiamos estos procesos debiéramos pensar en mejores formas de hacer nuestros estudios accesibles a quienes los viven con mayor profundidad y crudeza. Pero, quizá, aún nos falta comprender nuestro propio papel en el proceso y, reconociendo nuestros privilegios, comprometernos a utilizar nuestra posición de clase y nuestro prestigio para desenmascarar los discursos que, por un lado, reafirman la universalidad de los derechos humanos pero, por otro, fomentan la discriminación y legitiman la explotación. Afortunadamente, cada vez son más quienes lo están haciendo.

\section{Notas}

${ }^{1}$ La contingencia que llevó a Osiel a Alabama no niega la importancia de las redes sociales en el proceso migratorio internacional. Osiel inició un proceso de concentración de migrantes llaneros en dicho estado.

${ }^{2}$ El salario mínimo de 2004 era de 42.11 pesos, en la región. Actualmente, es de 47.60 pesos.

${ }^{3}$ Preparar y vender bolis es muy común en la comunidad. ${ }^{4}$ La producción de mango ha sido también importante. 
COMO AQUí, ALLÁ; COMO NOSOTROS, ELLOS:

LA INTERNACIONALIZACIÓN DE LA PRECARIEDAD EN EL

EJERCICIO CIUDADANO

T e mátic a

${ }^{5}$ En el año agrícola 1999-2000, Teocelo ocupó el lugar número once en producción de café, su principal producto comercial.

${ }^{6}$ Más de 37\% de los llaneros se distribuyen en otros estados sureños, además de 19\% que reside en Alabama (Censo comunitario, llevado a cabo en 2006).

${ }^{7} 65 \%$ de los condados tenían una tasa desempleo igual o mayor que la nacional, principalmente en donde predomina la población afro-americana (el "Black Belt") (ACPP 2006).

${ }^{8}$ La fuerza de trabajo de Alabama en 2005 era de 2.1 millones, incluyendo los empleados y los que buscan empleo (ACPP 2006).

${ }^{9}$ La expansión económica del estado no ha mejorado el ingreso medio de los hogares, al contrario, se ha reducido en 5\% entre 2000 y 2001, en comparación con 2004-05, cayendo de 39,465 a 37,502 dólares anuales. La pobreza infantil (menores de 18 años) en Alabama $(24.7 \%, 7.1$ puntos porcentuales mayor al promedio nacional), es sólo superada por el Distrito de Columbia y por Mississippi. También persiste la inequidad de género, pues para las mujeres, la percepción era de $76 \%$ de lo que recibían los hombres (ACPP 2006)

${ }^{10}$ El número de habitantes sin ningún seguro de salud se incrementó de 13.3\% en 2000 a 15.4\%, en 2005 (APP 2005).

\section{Bibliografía}

Alabama Forestry Commission, 2006, página web: www. forestry.state.al.us/

Alabama Poverty Project, 2005, página web: www.alabamapoverty.org/about.html

Antidifamation League, 2005, página web: http://www. adl.org/main_Extremism/immigration_extremists. htm?Multi_page_sections=sHeading_2

Arise Citizens' Policy Project (ACPP), 2006, The State of Working Alabama 2006, en colaboración con el Economic Policy Institute, para el análisis de datos del Current Population Survey de 2005, página web: www.arisecitizens.org
Camarota, Steven y McArdle, Nora, 2003, "Where Immigrants Live. An Examination of State Residency of the Foreign Born by Country of Origin in 1990 and 2000", Backgrounder, Center for Immigration Studies.

Cruz, Anabella, 2003, Distribución y Uso de la Tierra. Un Análisis Comparativo de dos lugares Migrantes del Municipio de Actopan: Santa Rosa y Coyolillo, Tesis de Licenciatura, Xalapa, Veracruz, Universidad,Veracruzana.

Harris, Ann, 2006, "Globalization and Poverty", National Bureau of Economic Research Working Paper No. 12347, julio.

Mohanty, Chandra, 2003, Feminism Without Borders. Decolonizing Theory. Practicing Solidarity, Duke University Press.

Hamilton, Spencer, et.al., 2006, La Migración y el Futuro de los Estados Unidos: Un Nuevo Capítulo, Resumen Ejecutivo, Grupo de Trabajo sobre Inmigración y el Futuro de los Estados Unidos.

Naciones Unidas, 2006, Resolution Adopted by the General Assembly, 60/251 Human Rights Council, abril, página web:http://daccessdds.un.org/doc/UNDOC/GEN/ N05/502/66/PDF/N0550266.pdf?OpenElement.

Paredes, Lorena, 1995, "Una Mirada al Período de Crisis de la Cafeticultura Mexicana, Recuento de Políticas Oficiales y Respuestas Campesinas", en Neoliberalismo y Campo. Cuadernos Agrarios, pp. 11-12, enero-diciembre, Nueva época.

Soysal, Yasemin, 2004, "Postnational Citizenship: Reconfiguring a Familiar Terrain", ponencia presentada en, Transforming Citizenship? Transnational Membership, Participation, and Governance, abril.

U.S. Census Bureau, 2003, Poverty in the United States 2002, documento en la página web: www.census. gov/prod/2003pubs/p60-222.pdf

University of Georgia, 2002, Study of Persistent Poverty in the South, página web: www.cviog.uga.edu/poverty/

Zamudio, Patricia, 2006, Why leave? Analyzing Citizenship Consciousness to Understand the Late Incorporation of Veracruzanos in the International Migration Process, Ponencia preparada para el XVI Congreso Internacional de Sociología, Durban, Sudáfrica, julio.

78 Revista LiminaR. Estudios sociales y humanísticos, año 5, vol. V, núm. 2, diciembre de 2007, Tuxtla Gutiérrez, Chiapas. ISSN: 1665-8027 